\title{
Development and Characterization of a \\ Thermoforming Apparatus Using Axiomatic Design Theory and Taguchi Method
}

\section{Trieu Khoa Nguyen}

Industrial University of Hochiminh city

Anh-Duc Pham ( $\square$ ducpham@dut.udn.vn )

The University of Danang - University of Science and Technology https://orcid.org/0000-0002-04009200

\section{Minh Quang Chau}

Industrial University of Hochiminh city

\section{Xuan Chien Nguyen}

Industrial University of Hochiminh city

\section{Hoang Anh Duong Pham}

Industrial University of Hochiminh city

\section{Manh Hung Pham}

Industrial University of Hochiminh city

\section{Trung Phi Nguyen}

Industrial University of Hochiminh city

\section{Hai Son Nguyen}

Cao Thang Technical College

\section{Original Article}

Keywords: Axiomatic design theory, Optimization, Taguchi technique, Thermoforming, Thickness uniformity

Posted Date: June 9th, 2020

DOl: https://doi.org/10.21203/rs.3.rs-33447/v1

License: (c) (i) This work is licensed under a Creative Commons Attribution 4.0 International License.

Read Full License 


\section{Title page}

\section{Development and Characterization of a Thermoforming Apparatus Using Axiomatic Design Theory and Taguchi Method}

Trieu Khoa Nguyen, born in 1981, is currently is Head of Manufacturing Division of the Faculty of Mechanical Engineering, Industrial University of Ho Chi Minh City, Vietnam. He received his Ph.D in Mechanical Engineering from Chonnam National University, Korea. His research interests include polymer science, multiscale manufacturing processes, 3D printing technology.

E-mail: nguyenkhoatrieu@iuh.edu.vn

Anh-Duc Pham, born in 1986, received Ph.D. degree from Soongsil University, Korea. He was a research associate in the IMSLab Soongsil University and is currently a researcher/lecturer at the Faculty of Mechanical Eng., University of Science and Technology- The University of Danang. Dr. Pham's research interests are mechatronics, control \& precision machine design, sustainable design \&manufacturing, applications of nanomaterials.

E-mail: ducpham@dut.udn.vn

Minh Quang Chau, born in 1970, received Ph.D. degree from the Institute of Mechanical Engineering, Hunan University, China, in 2013. He is currently the Dean of the Faculty of Mechanical Engineering, Industrial University of Ho Chi Minh City, Vietnam. His research interests are manufacturing, material, mechanics, reliability and optimization.

E-mail: chauminhquang@iuh.edu.vn

Xuan Chien Nguyen, received his received B.S. in Mechanical Engineering from Industrial University of Ho Chi Minh City, Vietnam in 2019.

E-mail: xuanchiencoi@gmail.com

Hoang Anh Duong Pham received his received B.S. in Mechanical Engineering from Industrial University of Ho Chi Minh City, Vietnam in 2019.

E-mail: duongphamck153@gmail.com

Manh Hung Pham received his received B.S. in Mechanical Engineering from Industrial University of Ho Chi Minh City, Vietnam in 2019.

E-mail: Phamhungctm12@gmail.com

Trung Phi Nguyen received his received B.S. in Mechanical Engineering from Industrial University of Ho Chi Minh City, Vietnam in 2019.

E-mail: sologoal5@gmail.com

Hai Son Nguyen, born in 1987, received his received M.S. degree from University of Technology, Vietnam National University - Ho Chi Minh City in 2013. Mr. Nguyen's research interests include metal \& plastic processing, manufacturing processes \& application of 3D printing technology.

E-mail: haisonlongan@gmail.com

\section{Corresponding author: Anh-Duc Pham E-mail: ducpham@dut.udn.vn} TrieuKhoa Nguyen E-mail: nguyenkhoatrieu@iuh.edu.vn 


\title{
Development and Characterization of a Thermoforming Apparatus Using Axiomatic Design Theory and Taguchi Method
}

\author{
Trieu Khoa Nguyen ${ }^{1 *} \cdot$ Anh-Duc Pham ${ }^{2 *} \cdot$ Minh Quang Chau ${ }^{1} \cdot X u a n$ Chien Nguyen ${ }^{1} \cdot H_{0 a n g}$ Anh Duong Pham ${ }^{1} \cdot$ Manh \\ Hung Pham ${ }^{1} \cdot$ Trung Phi Nguyen ${ }^{1} \cdot$ Hai Son Nguyen ${ }^{3}$
}

Received June xx, 201x; revised February xx, 201x; accepted March xx, 201x

(c) Chinese Mechanical Engineering Society and Springer-Verlag Berlin Heidelberg 2017

\begin{abstract}
'Abstract: In this study, an experimental investigation of the development of a thermoforming apparatus and the thickness uniformity of its samples was performed based on the axiomatic design theory in conjunction with the Taguchi method. Thermoforming is a powerful tool for both consumer product needs and packaging industry. Such traditional technology has been investigated in many aspects for a long time ago. However, there are still needs for the development and characterization of thermoforming devices aiming at shorter construction time and less cost involved. Therefore, an experimental analysis was performed to systematically realize all the functional structures of the device using axiomatic design theory. The combination of orthogonal array (OA) and analysis of variance revealed the influences of the relatival processing factors, showing that the thickness of the plastic sheet and areal draw ratio had crucial roles to play. Furthermore, an optimization process using the Taguchi method was utilized to determine all accurate and optimum processing parameters. The outcomes obviously verified that the present combination method can overcome the current development and optimization method's limitation and also conclusively give accurate optimal outcomes without using complicated algorithms and software solutions. Therefore, it promises a simple and powerful tool for engineers on-site in medium or small scale manufactories.
\end{abstract}

Keywords: Axiomatic design theory • Optimization • Taguchi technique $\bullet$ Thermoforming $•$ Thickness uniformity

Anh-Duc Pham, TrieuKhoa Nguyen,

ducpham@dut.udn.vn,nguyenkhoatrieu@iuh.edu.vn

1 Faculty of Mechanical Engineering, Industrial University of Ho Chi Minh city, Ho Chi Minh city, Vietnam

2 Faculty of Mechanical Engineering, The University of Danang University of Science and Technology, Da Nang city, Vietnam

Faculty of Mechanical Engineering Technology, Cao Thang Technical College, Ho Chi Minh city, Vietnam

* These authors equally contributed to this work as first author

\section{Introduction}

Thermoforming is one of the most popular and economical manufacturing technologies to fabricate plastic products [1]. By bringing a heated flat sheet of plastic into contact with a mold with desired shapes and utilizing a vacuum force or a pressure force or a combination of both, a thermoformed plastic product can be precisely fabricated. Generally, thermoforming has several benefits over other techniques such as low manufacturing cost, high manufacturing efficiency in a limited processing time, and high surface quality [2]. And it deals with large area thin wall plastic products which another powerful technique, injection molding, faces great difficulties. To these merits, there have been many investigations toward thermoforming technology.

Nowadays, thermoforming can be considered as a traditional manufacturing technique for plastic materials. Therefore, in many aspects of this traditional manufacturing process, in order to be accepted for publication, the authors used very complex optimization techniques. For instance, Sala et al. [3] proposed an optimization method for the preliminary set-up of the process parameters to achieve a better management of thickness distribution, cycle-time reduction and material saving. Using G'Sell's constitutive law and CoxMerz's empirical law to develop a FEM code, PAM-STAMP software solution was then utilized to simulate the thermoforming process for thickness prediction. However, this complexity process did not present optimized process parameters for a better control of thickness distribution yet. A commercial software solution was also used, but Abaqus ${ }^{\circledR}$, O'Connor et al. [4] utilized Ogden and 
Arruda-Boyce models to numerical simulate the thermoforming process for thickness distribution. Afterwards, the authors continued to use the Sweeny viscoelastic model to simulate and optimize the process [5]. However, optimized process parameters were still missed. Other authors also simulated the thermoforming process via Abaqus ${ }^{\circledR}$ using Ogden model [6]. Also using the Ogden model, in [7], Chang et al. combined with the Mooney-Livlin model to improve optimization quality. Azdast et al. [8] continued to utilized a Mooney-Livlin hyperelastic model as the constitutive equation for thickness distribution simulation. Similarly, the modified Lagrangian model and the Newton-Raphson method were used to simulate the thermoforming process, without optimized parameter results [9]. However, also optimizing the thermoforming process, Yang et al. [10] used the inverse neural network, a rather complex algorithm. Using the inputted part thickness distribution, this inverse step was also a difficulty for engineers on-site. In [11], the authors used an artificial neural network model (with back propagation and the Levenberg-Marquardt training algorithm) combined with an analysis of variance (ANOVA). In particular, the process has been optimized, optimal parameters were able to predict, but the benefits achieved commensurate with the complexity of the optimization process or have not been verified. Also using an algorithm, the authors in [12] used the Van der Waals equation and Prony series relaxation function to build an 18parameters model to control and optimize the thickness of the products for a plug assisted thermoforming. Also using the Van der Waals equation, but Makradi et al. from France [13] combined with Bergstrom and Boyce's model based on Doi and Edwards theory to model the thermoforming process. In addition to amorphous resins [13], these authors have also applied their model to semi-crystalline resins [14]. As for traditional optimization methods, in other words, simple optimization methods, like the Taguchi method, must be combined with one or more other algorithms. For instance, in [15], the authors combined the Taguchi method with utility concept or utility function. The optimum setting of the process conditions for a multi-characteristic product was determined. However, a different set of optimal conditions was achieved for a different set of weights originated from the utility concept, which had a certain degree of uncertainty. While Bae et al. [16] performed a response surface analysis to obtain a regression equation. The optimal process parameters were then determined utilizing the sequential quadratic-programming (SQP) method. As short, the common disadvantage of these investigations is too complicated for engineers to apply on-site. Some studies even did not result in any operation parameters which were important in real manufacturing.

Our survey also reveals a fact that the construction step, or design step, which is a crucial step in the development of a thermoforming device, is not gain much attention from researchers. Therefore, selection of an appropriate design approach for the thermoforming device is a must. There is a wide range of software solutions available nowadays for finite element analysis both in force analysis, durability calculation and optimization for a single machine element. Meanwhile, the design of machine systems, although there are several supporting tools such as idea tree, decision matrix method, design for manufacturing (DFM), Quality Function Deployment (QFD), design for assembly (DFA) and so on, but not yet systematic, mainly based on trial and error, prototyping - testing - editing, based on subjective assessments, poor management of design information [17]. Originating from that need, Professor Nam Pyo Suh from MIT, USA, established a novel design theory according to certain rules, provided a scientific and systematic basis for making design decisions [18].

Axiomatic Design Theory (ADT) right after being developed and introduced by Professor Nam Pyo Suh in 2001 [18] has been widely applied [19]. Also, in 2001, Lee et al. from the USA successfully applied the ADT to develop a chemical-mechanical polishing (CMP) in industrial scale. The device then operated without significant errors or drawbacks and was then used as an example of applying the ADT [20]. Beom-Seon Jang et al. [21] from South Korea also used this theory to design ship propellers. Many other authors from South Korea utilized the ADT for their investigations, such as Bae, Tae-Sung and Lee, Kwon-Hee designed a main starting valve [22], Hwang et al. [23] developed a vibratory gyroscope using an unbalanced inner torsion gimbal, Park, Jong Man [24] improved and evaluated reconfiguration manufacturing system (RMS) adaptability in small and medium manufacturing industry. Bang, In Cheol \&Heo, Gyunyoung [25] constructed nanofluid coolants, and so on. In addition, R.J. Urbanic et al. from Canada [26], also applied the ADT to develop a type of connecting rod, which has plenty of room for further improvements according to market requirements. Meanwhile, in China, Dunbing Tang et al. [27] used the ADT to solve the limitation of Design Structural Matrix (DSM) which is very difficult to create a design matrix for a new product that has never been designed before. And Feng-Tsai Weng \&Shien-Ming Jenq from Taiwan [28] successfully applied the ADT to agile manufacturing, a highly developed form of lean 
manufacturing. As a typical use of the ADT to overcome the limitations of existing design methods, Jose' Antonio Carnevalli and colleagues from Brazil [29] using the ADT to overcome the three main weaknesses of the throne method. The quality house (quality function deployment method - QFD) includes (1) difficulty in expressing customer needs, (2) identifying and prioritizing quality characteristics and (3) handling large matrices. Meanwhile, António M. Gonçalves-Coelho et al. [30] from Portugal used the ADT to solve the difficulties in designing a crawler crane. Recently, Panday H. and Bhattacharya B. from India [31] successfully combined the ADT and TRIZ in the context of system design. And many more researchers have successfully applied the ADT to their designs, theoretical investigations or practical productions showing the power of this tool.

To the needs of development and characterization of a thermoforming device to be applied in medium or small-scale manufactories, a new technique integrating between the ADT and the Taguchi method is presented in this study. At first, the axiom of maintaining the independence of functional requirements (FRs) is utilized to explore all needed DPs, or physical components of the apparatus. The Taguchi method is then applied with investigation for the major processing conditions of the thermoforming process, giving out optimal values. These obtained values were then verified for a better thickness distribution result. Using this method, the influences of processing conditions on thickness uniformity of the thermoformed part were analyzed utilizing the conditions that resulted minimum thickness variation.

\section{Design and characterization methods}

\subsection{Axiomatic design theory}

The main theme of this investigation is based on axiom 1, the independence axiom. This axiom elucidates the independence of FRs should be maintained by a suitable selection of DPs [18]. Then, the FRs are stated as the minimal combination of independent requirements which characterize the design targets Error! Reference source not found.. Mathematically, the correlation between the DPs and the FRs vectors are described in matrix form as [32]:

$$
\{F R s\}=|A|\{D P s\}
$$

where FRs is the vector of functional requirement, $\mathrm{A}$ is the design matrix that characterize the design, DPs is the vector of design parameters.

To obey the independence axiom, the design matrix A must be either diagonal or triangular [33]. The FR is able to be fulfilled independently by one DP when the design matrix is the diagonal matix. And the design is stated as an uncoupled design. In the case of a triangular matrix, the independence of FRs may be maintained if and only if the DPs are defined in a correct sequence. And the design is stated as a decoupled design. With any other forms, the design matrix will be a coupled design [23].

\subsection{Design of experiment (DOE)}

One of many DOE approach utilized in this study is The Taguchi method [34]. In particular, it investigates the effects of various factors on the average results and the process variance [35]. Additionally, an orthogonal array is implemented to characterize the influences of certain factors on the process by just conducting a minimal and optimized number of experiments. Therefore, the Taguchi method is a hugely efficient method and is employed in many fields due to its advantage of identifying the importance of each factor influencing product quality [36].

The signal-to-noise $(\mathrm{S} / \mathrm{N})$ ratio is particularly utilized in the Taguchi method to study the influence of each factor [37]. Because the uniformity, the typical of interest in this investigation, should be as close as possible to zero, a "smaller the better" formula is employed for the S/N ratio calculation as follows [39],[40]:

$$
S / N=-10 \log \left(\frac{1}{n} \sum_{1}^{n} y_{i}^{2}\right)
$$

where $\mathrm{y}$ is the observation, $\mathrm{n}$ is the number of experiments.

The effects of processing conditions can also be analysed using an ANOVA study [38], which determines the percentage that each parameter contributes [36]. The total sum of squared deviations $\mathrm{SS}_{\mathrm{T}}$ from the total mean $\mathrm{S} / \mathrm{N}$ ratio, is described below:

$$
S S_{T}=\sum_{i=1}^{n}\left(S S_{i}-S S_{M}\right)^{2}
$$

where $\mathrm{SS}_{\mathrm{M}}$ is the sum of squared deviations of all parameters.

\section{Analysis and discussions}

\subsection{Analyzing of a desired thermoforming apparatus using the ADT}

Among the common thermoforming principles [1], the chosen thermoforming principle was vacuum forming with male mold, which was the most simple and low cost. From this working principle, the thermoforming device was decomposed into functional requirements and physical components to implement them as illustrated in Figure 1. The basic FR of designing a thermoforming device could be described as "fabricate thermoformed samples". The corresponding DP in the physical domain is "thermoforming apparatus". Because the design matrix has 
only one element, this is an uncoupled mapping from FR to DP. Consequently, the FRs at first level were decomposed from the basic FR. Then a zigzagging process was used to decompose the design into hierarchies by alternating between parts of domains.

The process of decomposition and mapping was continued until the design solutions could be implemented. The detailed FRs and DPs were summarized in Table 1.

The design equation for the selected FRs and DPs is as:

$$
\left\{\begin{array}{l}
F R_{1} \\
F R_{2} \\
F R_{3} \\
F R_{4} \\
F R_{5} \\
F R_{6} \\
F R_{7} \\
F R_{8}
\end{array}\right\}=\left[\begin{array}{cccccccc}
\times & 0 & 0 & 0 & 0 & 0 & 0 & 0 \\
0 & \times & 0 & 0 & 0 & 0 & 0 & 0 \\
0 & 0 & \times & 0 & 0 & 0 & 0 & 0 \\
0 & 0 & 0 & \times & 0 & 0 & 0 & 0 \\
0 & 0 & 0 & 0 & \times & 0 & 0 & 0 \\
0 & 0 & 0 & 0 & 0 & \times & 0 & 0 \\
0 & 0 & 0 & 0 & 0 & 0 & \times & 0 \\
0 & 0 & 0 & 0 & 0 & 0 & 0 & \times
\end{array}\right]\left\{\begin{array}{l}
D P_{1} \\
D P_{2} \\
D P_{3} \\
D P_{4} \\
D P_{5} \\
D P_{6} \\
D P_{7} \\
D P_{8}
\end{array}\right\}
$$

In Eq. (4), the design matrix [A] is a diagonal one. Hence, each of the FRs can be fulfilled independently by a correspondent DP. Therefore, the design can be considered as an uncoupled design. Hence, from the ADT's point of view, the initial selections of FRs and DPs were suitable for the next decomposition steps.

From Table 1, the design equations for FRs and DPs of the lower level are yielding coupled design, except the design equation for $\mathrm{FR}_{6 \mathrm{~s}}$ and $\mathrm{DP}_{6 \mathrm{~s}}$ :

$$
\left\{\begin{array}{l}
F R_{61} \\
F R_{62} \\
F R_{63}
\end{array}\right\}=\left[\begin{array}{ccccc}
\times & 0 & 0 & 0 & 0 \\
0 & \times & 0 & 0 & 0 \\
0 & 0 & \times & \times & \times
\end{array}\right]\left\{\begin{array}{l}
D P_{61} \\
D P_{62} \\
D P_{63} \\
D P_{64} \\
D P_{65}
\end{array}\right\}
$$

Because there are more $\mathrm{DP}_{6 \mathrm{~s}}$ than $\mathrm{FR}_{6 \mathrm{~s}}$, based on Theorem 3 , the design is called redundant design. From the ADT's viewpoint, to solve this redundant design, the design parameter " $\mathrm{DP}_{63}$ : Fitting" was selected as the key DP. The size of this brass fitting is usually $\mathrm{H}=12 \mathrm{~mm}$. Then, based on constraint " $\mathrm{C}_{62}$ : Flexible connection" and key DP, a silicone connection tubing and a quick coupling for the vacuum chamber side were selected to connect the vacuum pump and the vacuum chamber.

\subsection{The apparatus fabrication and preliminary experiments}

On the ground of the achieved results of the concept design, the apparatus was successfully designed using Solid-Works®. The apparatus was then fabricated as shown in Figure 2.

During the preliminary tests, because of insufficient clamping force, the PET plastic sheet was deformed during heating. Hence, the design matrix of the clamping device needed to be re-considered. The original design matrix was stated as an uncoupled design:

$$
\left\{\begin{array}{l}
F R_{21} \\
F R_{22} \\
F R_{23}
\end{array}\right\}=\left[\begin{array}{ccc}
\times & 0 & 0 \\
0 & \times & 0 \\
0 & 0 & \times
\end{array}\right]\left\{\begin{array}{l}
D P_{21} \\
D P_{22} \\
D P_{23}
\end{array}\right\}
$$

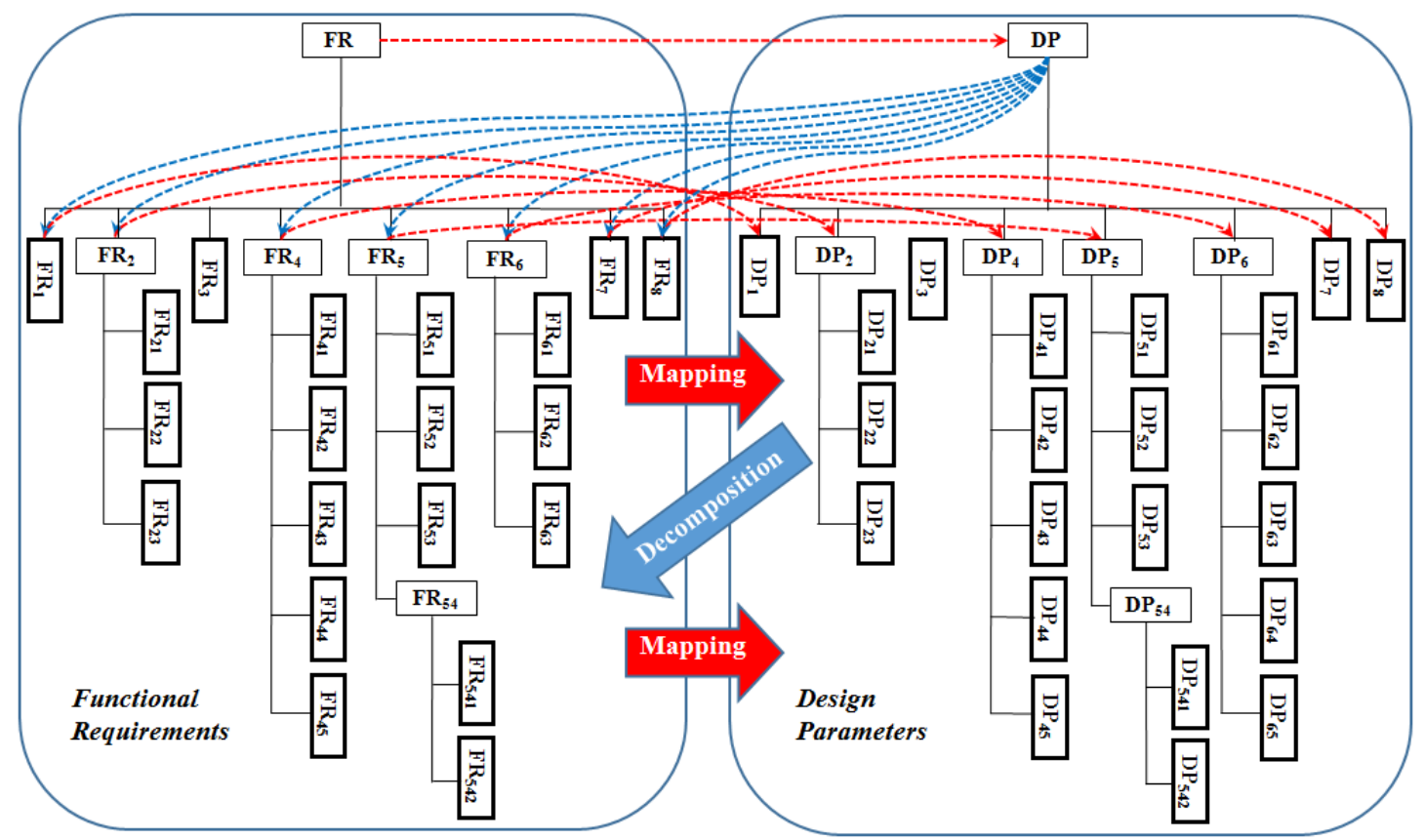

Figure 1 Mapping and decomposition process 
Table 1 Detailed results of FRs and DPs in Figure 1

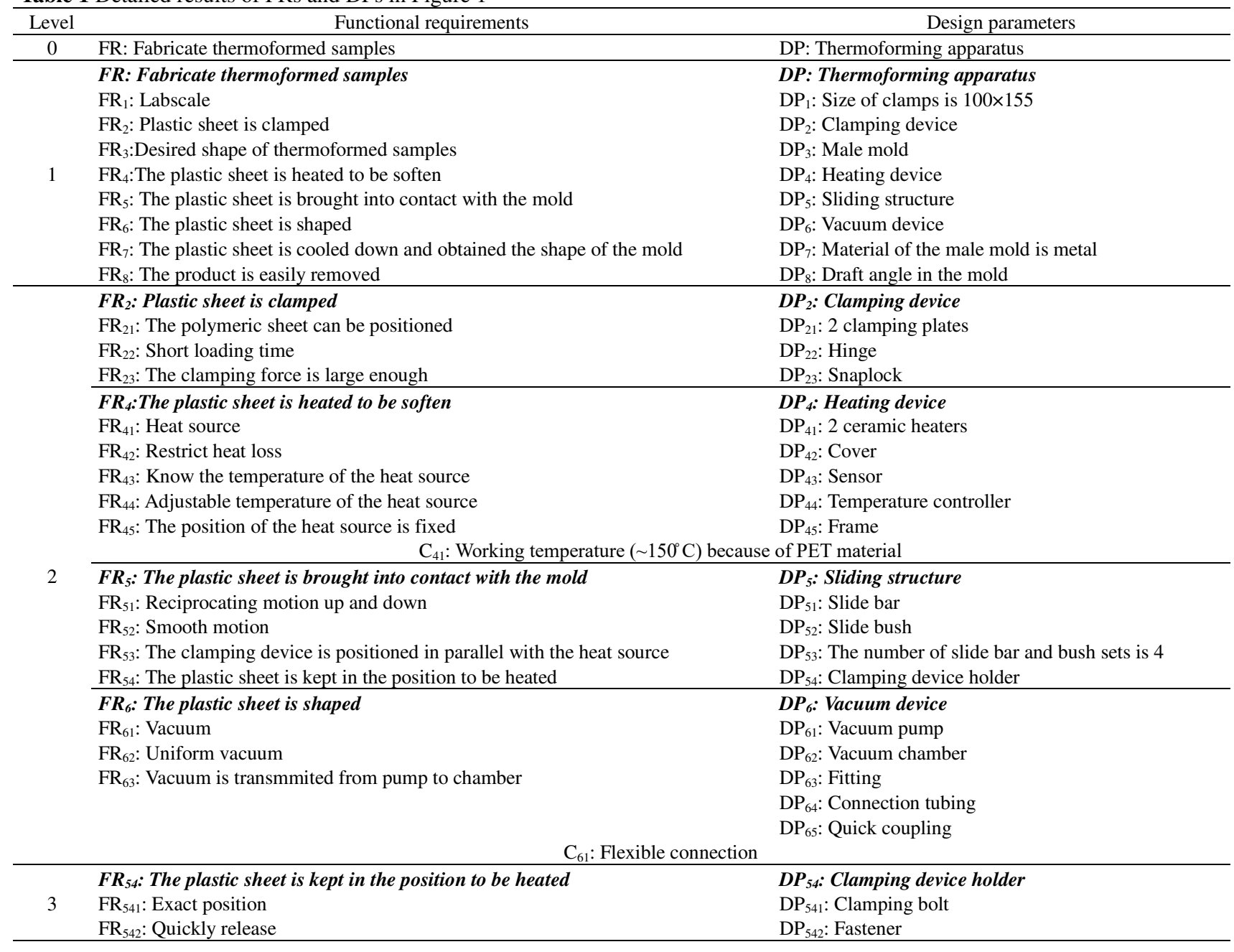

After the preliminary experiments, the design matrix for this device was re-established as:

$$
\left\{\begin{array}{l}
F R_{21} \\
F R_{22} \\
F R_{23} \\
F R_{24}
\end{array}\right\}=\left[\begin{array}{cccc}
\times & 0 & 0 & 0 \\
0 & \times & 0 & 0 \\
0 & 0 & \times & \times \\
0 & 0 & \times & \times
\end{array}\right]\left\{\begin{array}{l}
D P_{21} \\
D P_{22} \\
D P_{23} \\
D P_{24}
\end{array}\right\}
$$

where $\mathrm{FR}_{24}$ : Tightly sealing, no pressure leakage; $\mathrm{DP}_{24}$ : The flatness of the clamping plates. Because of these new DP and FR, the design matrix was no longer a diagonal one. Hence, it became a coupled design.

To overcome this problem, a soft rubber pad with tape attached was used. Thus, the tightness no longer depended on the flatness of the clamping plates. And snaplock was replaced by manual clamping. Then the Eq. 7 became:

$$
\left\{\begin{array}{l}
F R_{21} \\
F R_{22} \\
F R_{23} \\
F R_{24}
\end{array}\right\}=\left[\begin{array}{cccc}
\times & 0 & 0 & 0 \\
0 & \times & 0 & 0 \\
0 & 0 & \times & 0 \\
0 & 0 & 0 & \times
\end{array}\right]\left\{\begin{array}{l}
D P_{21} \\
D P_{22} \\
D P_{23} \\
D P_{24}
\end{array}\right\}
$$

where $\mathrm{FR}_{21}$ : The polymeric sheet can be positioned; $\mathrm{FR}_{22}$ : Short loading time; $\mathrm{FR}_{23}$ : The clamping force is large enough; $\mathrm{FR}_{24}$ : Tightly sealing, no pressure leakage; and $\mathrm{DP}_{21}$ : 2 clamping plates; $\mathrm{DP}_{22}$ : Gravity of the clamping plates; $\mathrm{DP}_{23}$ : Manual clamping; $\mathrm{DP}_{24}$ : A soft rubber pad with tape attached.

The thermoformed samples were then fabricated. By consideration of the deformation of the $10 \mathrm{~mm} \times 10 \mathrm{~mm}$ net, the quality of the samples was checked, Figure 3.

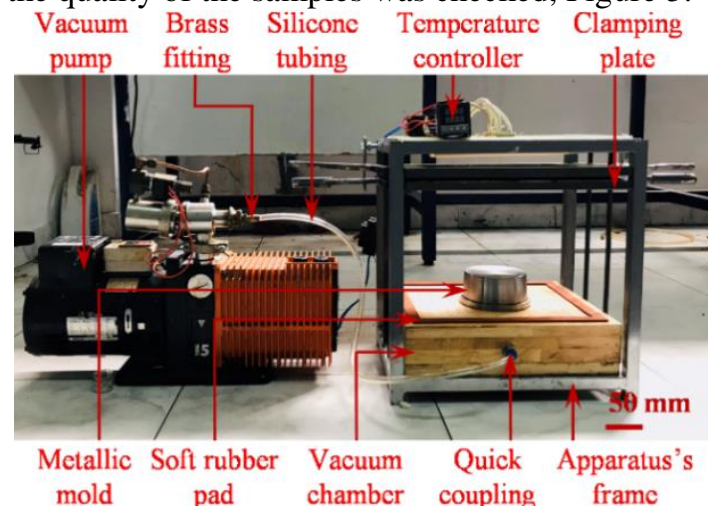

Figure 2 Photograph of the lab-scale thermoforming setup employing the ADT 


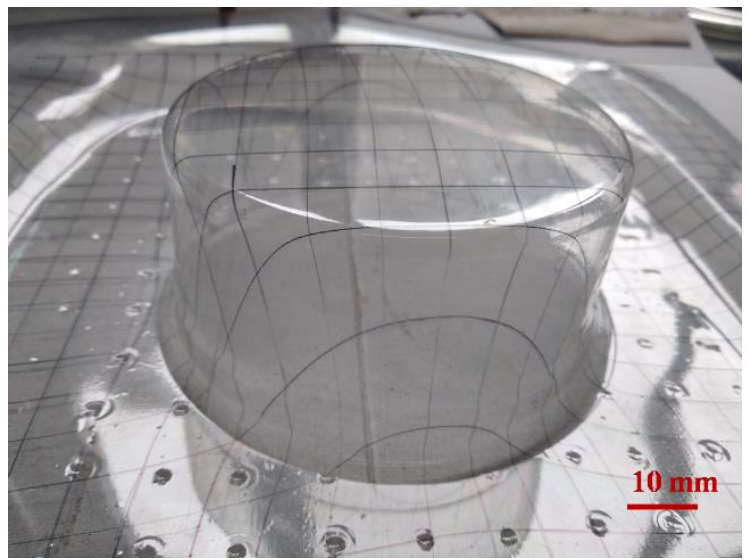

Figure 3 Thermoformed sample with its deformed net

\subsection{Effect of thermoforming parameters}

\subsubsection{Selection of thermoforming parameter}

In our thermoforming process, a thin plastic sheet was clamped in a clamping device at a certain distance with the heater. It was then heated to a certain temperature well above its glass transition temperature in order that it became soft and rubbery. The plastic sheet was then brought into contact with the mold and stretched to obtain the shape of the mold using differential pressure. The subsequent factors may influence the quality of the thermoformed samples [15]:

1. Temperature related parameters - heating temperature and heating time;

2. Pressure related parameters - positive pressure, vacuum pressure;

3. Material related parameters - type of material, thickness;

4. Equipment related parameters - assisting plug, moving speed, moving distance or distance between heater and plastic sheet.

Considering the results of the preliminary experiments, five processing parameters, including heating temperature $\left({ }^{\circ} \mathrm{C}\right)$, distance between heater and plastic sheet $(\mathrm{mm})$, heating time (s), draw ratio (-), and thickness of the plastic sheet $(\mathrm{mm})$, were investigated in the inchoative approach towards characterization. It is worth noting that three levels of the processing parameter for each factor were set relied on the suggested ranges. Table 2 demonstrates the processing factors and the three levels of them used in this investigation. Using this method, a DOE-based study could be systematically built.

From the number of determined factors as well as their corresponding levels, a subset of the $\mathrm{L}_{18}\left(3^{5}\right)$ OA was chosen as presented in Table 3. Experimental experiments of the thermoforming process were carried out utilizing the condition sets of the OA. The uniformity of the thermoformed parts, obtained from the experiments, and the respective $\mathrm{S} / \mathrm{N}$ ratios were also shown in Table 3. Since the uniformity, the target of this investigation, should be minimized in order to get a precious sample, the "smaller the better" formula of the $\mathrm{S} / \mathrm{N}$ ratio was utilized to determining each $\mathrm{S} / \mathrm{N}$ ratio.

Table 2 Processing conditions and their specified levels analysed in the current investigation.

\begin{tabular}{clccc}
\hline \multirow{2}{*}{ Symbol } & \multicolumn{2}{c}{ Parameter } & \multicolumn{3}{c}{ Level } \\
\cline { 3 - 5 } & & 1 & 2 & 3 \\
\hline A & Heating temperature $\left({ }^{\circ} \mathrm{C}\right)$ & 38 & 300 & 310 \\
B & Distance $(m m)$ & 40 & 42 \\
C & Heating time (s) & 26 & 27 & 28 \\
D & Draw ratio (-) & 1.5 & 2 & 2.5 \\
E & Thickness (mm) & 0.2 & 0.25 & 0.3 \\
\hline
\end{tabular}

\subsubsection{Characterization of thermoforming parameters}

The resulting $\mathrm{S} / \mathrm{N}$ ratios for each processing factor are shown in Table 4. The outcomes are also illustrated in Figure 4, which plainly illustrates the influences of the processing factors. For example, the uniformity of the thermoformed sample was observed to increase with not only increasing draw ratio (parameter D) but also thickness (parameter E) within the characteristic range of utilizing. By considering the difference between the minimum and maximum $\mathrm{S} / \mathrm{N}$ ratio results, the contribution of each factor was also achieved. Figure 5 presents the contribution chart of the processing factors. As presented, the draw ratio was determined to be the most important factor affecting uniformity.

To study more about the contributions of the related processing factors, an ANOVA consideration was performed as listed in Table 5. Having an agreement with the $\mathrm{S} / \mathrm{N}$ ratio study, draw ratio and thickness were considered to be significant factors with respect to uniformity improvement. Even though apparently there was a qualitative similarity between ANOVA studies and the $\mathrm{S} / \mathrm{N}$ ratio, a slight discrepancy in the magnitudes of the contributions of processing parameters was still observed. The ANOVA investigation demonstrated solely two parameters, draw ratio and thickness, as having higher $F$ results than $F_{(0.05,2,7)}$, thereby indicating that only these two parameters were statistically meaningful.

It is worth noting that the three parameters, heating temperature, heating time, distance show a similar trend. When their values were smaller, the thermoformed samples did not replicate the contour of the mold completely. Therefore, the uniformity, which was the difference between the maximum and minimum thickness of the 
thermoformed sample, became larger. While with greater values of these parameters, the samples deformed too much. As a result, the uniformity also became high. In addition, when the heating time was too long or the heating temperature was too high or the distance was too close, discoloration phenomena occurred.

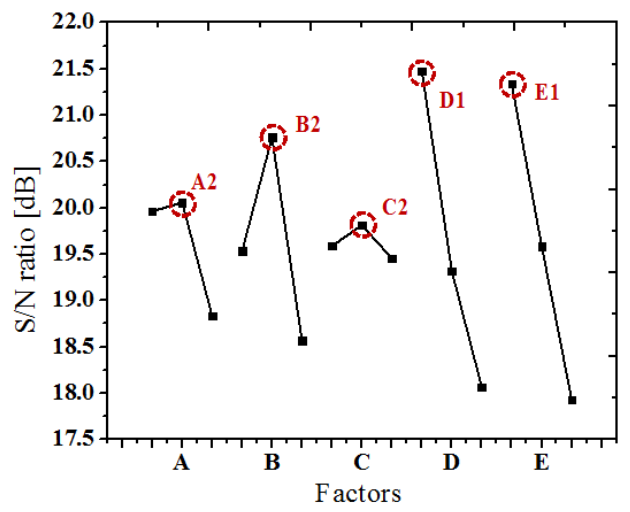

Figure 4 Results of $\mathrm{S} / \mathrm{N}$ ratio study illustrating the influence of processing conditions on the uniformity

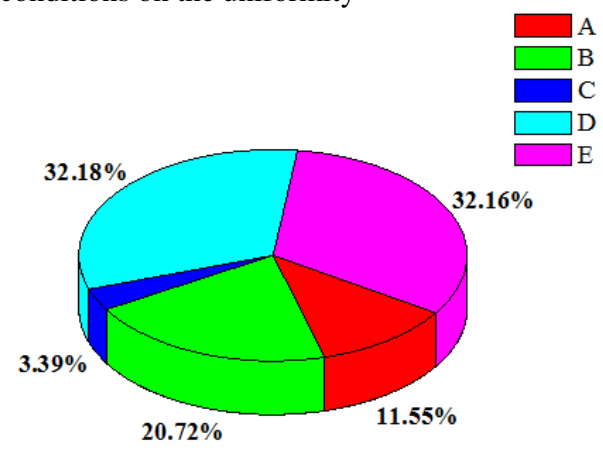

Figure 5 Contribution chart of each processing condition in the

$$
\mathrm{S} / \mathrm{N} \text { ratio study }
$$

\subsubsection{Validation test}

Through the S/N ratio study, it was found that better uniformity could be achieved using the processing parameters of A2-B2-C2-D1-E1 as indicated in Figure 4. This result was then verified using a commercial software solution, Minitab®. Validation results using Minitab® (Figure 6) showed consistency with the manual calculation results using Excel®. Different from academic fields, engineers in manufactories only utilize commercial software solutions, such as Minitab®, to minimize the time of DOE and analysis of results.

An additional experiment was performed under this condition as a validation test, indicating that the maximal uniformity in the sample was $0.06 \mathrm{~mm}$. This outcome was smaller, or better, than the uniformity outcomes of all the cases evaluated in the OA showed in Table 4.
Figures 7 and 8 illustrate the thermoformed sample from the validation test and its thickness distribution under the processing parameters in the $\mathrm{S} / \mathrm{N}$ ratio study. Via the validation test, the Taguchi method showed a better results of processing parameters for a better uniformity.

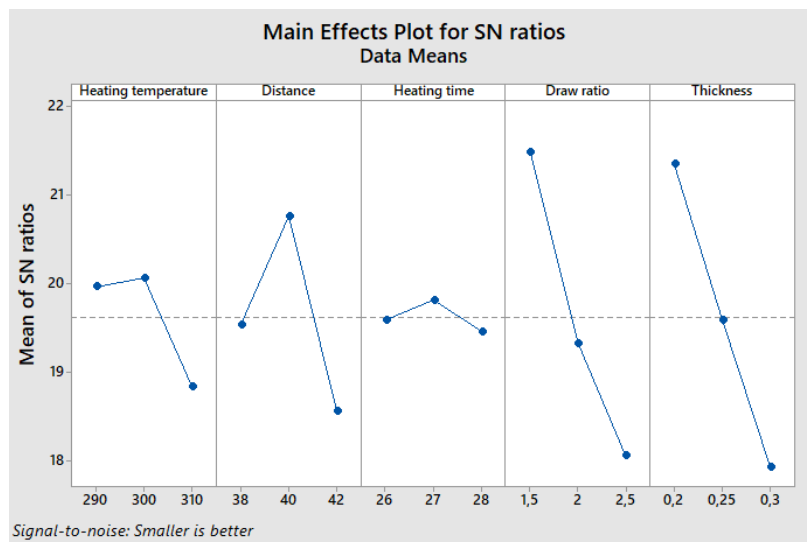

Figure 6 Validation using a commercial software solution Minitab®

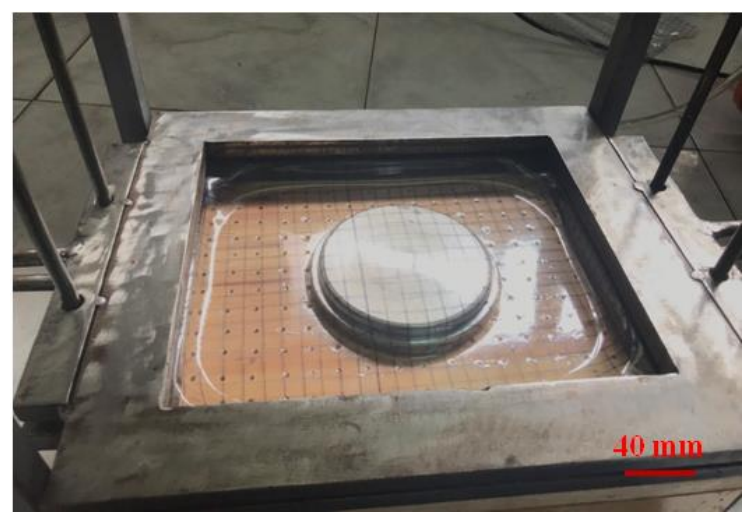

Figure 7 Validation experiment under the recommended parameters from $\mathrm{S} / \mathrm{N}$ ratio analysis

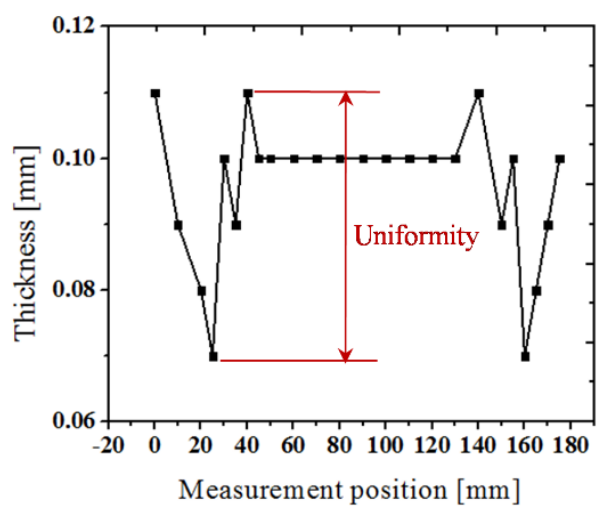

Figure 8 Thickness distribution of the validation sample and its uniformity value 
Table 3 The OA utilized in the current investigation: Detailed parameters for experimental combinations and achieved unifomity (MSD is mean standard deviation).

\begin{tabular}{|c|c|c|c|c|c|c|c|c|}
\hline \multirow{2}{*}{ No. } & \multicolumn{5}{|c|}{ Processing parameters } & \multirow{2}{*}{ Uniformity } & \multirow{2}{*}{ MSD } & \multirow{2}{*}{$\mathrm{S} / \mathrm{N}$ ratio } \\
\hline & A & $\mathrm{B}$ & $\mathrm{C}$ & $\mathrm{D}$ & $E$ & & & \\
\hline 1 & 1 & 1 & 1 & 1 & 1 & 0.073 & 0.00533 & 22.73354 \\
\hline 2 & 1 & 2 & 2 & 2 & 2 & 0.1 & 0.01 & 20 \\
\hline 3 & 1 & 3 & 3 & 3 & 3 & 0.18667 & 0.03484 & 14.57866 \\
\hline 4 & 2 & 1 & 1 & 2 & 2 & 0.11 & 0.0121 & 19.17215 \\
\hline 5 & 2 & 2 & 2 & 3 & 3 & 0.12667 & 0.01604 & 17.94675 \\
\hline 6 & 2 & 3 & 3 & 1 & 1 & 0.08 & 0.0064 & 21.9382 \\
\hline 7 & 3 & 1 & 2 & 1 & 3 & 0.12333 & 0.01521 & 18.17839 \\
\hline 8 & 3 & 2 & 3 & 2 & 1 & 0.09 & 0.0081 & 20.91515 \\
\hline 9 & 3 & 3 & 1 & 3 & 2 & 0.16333 & 0.02668 & 15.7385 \\
\hline 10 & 1 & 1 & 3 & 3 & 2 & 0.11333 & 0.01284 & 18.91285 \\
\hline 11 & 1 & 2 & 1 & 1 & 3 & 0.07667 & 0.00588 & 22.30787 \\
\hline 12 & 1 & 3 & 2 & 2 & 1 & 0.08667 & 0.00751 & 21.24296 \\
\hline 13 & 2 & 1 & 2 & 3 & 1 & 0.09 & 0.0081 & 20.91515 \\
\hline 14 & 2 & 2 & 3 & 1 & 2 & 0.07 & 0.0049 & 23.09804 \\
\hline 15 & 2 & 3 & 1 & 2 & 3 & 0.13667 & 0.01868 & 17.28675 \\
\hline 16 & 3 & 1 & 3 & 2 & 3 & 0.13667 & 0.01868 & 17.28675 \\
\hline 17 & 3 & 2 & 1 & 3 & 1 & 0.09667 & 0.00934 & 20.29447 \\
\hline 18 & 3 & 3 & 2 & 1 & 2 & 0.09333 & 0.00871 & 20.59926 \\
\hline \multicolumn{6}{|c|}{ Sum } & 1.953 & 0.22935 & \\
\hline \multicolumn{6}{|c|}{ Average } & 0.1085 & & 19.61919 \\
\hline
\end{tabular}

Table 4 S/N ratio outcomes for each processing condition.

\begin{tabular}{ccccccc}
\hline Parameters & A & B & C & D & E & Total \\
\hline Level 1 & 19.96265 & 19.53314 & 19.58888 & 21.47588 & 21.33991 & 19.58680 \\
Level 2 & 20.05951 & 20.76038 & 19.81375 & 19.31729 & 58.85757 \\
Level 3 & 18.83542 & 18.56406 & 19.45494 & 18.06440 & 17.93086 & \\
\hline Difference & 1.22409 & 2.19632 & 0.35881 & 3.41149 & 3.40905 & 10.59976 \\
Contribution \% & 11.55 & 20.72 & 3.39 & 32.18 & 32.16 & 100 \\
\hline
\end{tabular}

Table 5 Results from ANOVA study.

\begin{tabular}{|c|c|c|c|c|c|c|c|}
\hline Parameters & $\mathrm{S}$ & $\mathrm{f}$ & $\mathrm{V}$ & $\mathrm{F}$ & $\mathrm{F}(0.05,2,7)$ & $\mathrm{P} \%$ & Rank \\
\hline A & 0.00072878 & 2 & 0.000364389 & 1.43315 & 9.54658 & 4.18 & \\
\hline B & 0.00290915 & 2 & 0.001454574 & 5.72089 & 9.54658 & 16.67 & 3 \\
\hline $\mathrm{C}$ & 0.0002747 & 2 & 0.000137352 & 0.54021 & 9.54658 & 1.57 & \\
\hline $\mathrm{D}$ & 0.00566804 & 2 & 0.002834019 & 11.14629 & 9.54658 & 32.48 & 2 \\
\hline $\mathrm{E}$ & 0.00609026 & 2 & 0.00304513 & 11.97660 & 9.54658 & 34.90 & 1 \\
\hline Error & 0.0017798 & 7 & 0.000254257 & & & & \\
\hline Total & 0.01745072 & 17 & & & & & \\
\hline
\end{tabular}

It should be pointed that Jeon, Byung Joo et al. [41] utilized a combination of the ADT and the Taguchi method to optimize a highly foamed polyolefin extrusion process to the fabrication of insulation for coaxial cable. According to their optimization flow chart, they used the ADT to design the process parameters. After an $\mathrm{S} / \mathrm{N}$ analysis using the Taguchi method, they employed the ADT again to optimize those parameters, establishing a fairly complicated optimization process. While, in this study, a simple linear combination of the ADT and the Taguchi method for development and characterization of a thermoforming apparatus was proposed. Utilizing the advantages of the ADT in systematically realizing all the functional structures of the device as well as the Taguchi method in characterizing the effects of the processing parameters, the proposed method promises a simple but powerful tool for engineers on-site.

\section{Concluding remarks}

In the current investigation, a combination technique was utilized to develop a thermoforming apparatus and study the influences of processing conditions on the uniformity of its products, and also to define the optimum parameters for a minimal difference in thickness. The combination technique utilized in this investigation basically included the ADT utilized in conjunction with the orthogonal array technique of the Taguchi method. At first, the ADT was utilized in systematically realizing all the functional 
structures of the device. In the experiments of the thermoforming process, five processing factors were then examined. Using the S/N ratio study and ANOVA on the basis of the Taguchi method having an $\mathrm{L}_{18}\left(3^{5}\right)$ orthogonal array, the draw ratio and thickness of the plastic sheet were determined as the most important parameters for the minimization of the uniformity in the final plastic product. Through this, the optimum parameter results were also effectively collected and confirmed via an extra experiment.

The simple and preeminent presentation of the combination method utilized in the current investigation presents its utility in many manufacturing fields and existent manufacturing locations, where commercial tools for optimizing are not consistently at hand. The current study was also carried out towards filling the gap between academics and industries. The proposed method promised a simple but powerful tool for engineers on-site to develop and characterize new devices for manufacturing quickly and effectively.

\section{Declaration}

\section{Acknowledgements}

This work was supported by the Research Program of Industrial University of Ho Chi Minh City, Vietnam under grant number 20/1.1CK01.

\section{Availability of data and materials}

The data during the current study are available from the corresponding author on reasonable request.

\section{Authors' contributions}

The author' contributions are as follows: TK Nguyen and AD Pham were in charge of the whole trial; TK Nguyen and AD Pham wrote the manuscript; MQ Chau and HS Nguyen supported for optimization theory and building experiment; XC Nguyen, HAD Pham, MH Pham, TP Nguyen assisted with sampling and laboratory analyses. All authors read and approved the final manuscript.

\section{Competing interests}

The authors declare that there are no conflicts of interest regarding the publication of this paper.

\section{References}

[1] J. L. Throne. Introduction to Thermoforming, in Understanding Thermoforming. ed: Carl Hanser Verlag GmbH \& Co. KG, 2008, 1-7.

[2] T. K. Nguyen and B.-K. Lee. Investigation of processing parameters in micro-thermoforming of micro-structured polystyrene film.
Journal of Mechanical Science and Technology, 2019, 33: 5669-5675.

[3] G. Sala, L. Di Landro, and D. Cassago. A numerical and experimental approach to optimise sheet stamping technologies: polymers thermoforming. Materials \& Design, 2002, 23(1): 21-39.

[4] C. P. J. O'Connor, G. Menary, P. J. Martin, and E. McConville. Finite element analysis of the thermoforming of Polypropylene. International Journal of Material Forming, 2008, 1: 779-782.

[5] C. P. J. O'Connor, P. J. Martin, and G. Menary. Viscoelastic Material Models of Polypropylene for Thermoforming Applications. International Journal of Material Forming, 2010, 3: 599-602.

[6] M. Ghobadnam, P. Mosaddegh, M. Rezaei Rejani, H. Amirabadi, and A. Ghaei, Numerical and experimental analysis of HIPS sheets in thermoforming process. The International Journal of Advanced Manufacturing Technology, 2015, 76: 1079-1089.

[7] Y.-W. Chang and J.-H. Cheng. Numerical and experimental investigation of polycarbonate vacuum-forming process. Journal of the Chinese Institute of Engineers, 2013, 36(7): 831-841.

[8] T. Azdast, A. Doniavi, S. Rash Ahmadi, and E. Amiri. Numerical and experimental analysis of wall thickness variation of a hemispherical PMMA sheet in thermoforming process. The International Journal of Advanced Manufacturing Technology.2013, 64: 113-122.

[9] M. K. Warby, J. R. Whiteman, W. G. Jiang, P. Warwick, and T. Wright. Finite element simulation of thermoforming processes for polymer sheets. Mathematics and Computers in Simulation, 2003, 61(3-6): 209-218.

[10] C. Yang and S.-W. Hung. Modeling and Optimization of a Plastic Thermoforming Process. Journal of Reinforced Plastics and Composites, 2004, 23(1): 109-121.

[11] W. D. O. Leite, J. C. Campos Rubio, F. Mata Cabrera, A. Carrasco, and I. Hanafi. Vacuum Thermoforming Process: An Approach to Modeling and Optimization Using Artificial Neural Networks. Polymers, 2018, 10(2): 143.

[12] R. McCool, P. J. Martin, and E. Harkin-Jones, Process modelling for control of product wall thickness in thermoforming. Plastics, Rubber and Composites, 2006, 35(8): 340-347.

[13] A. Makradi, S. Belouettar, S. Ahzi, and S. Puissant. Thermoforming process of amorphous polymeric sheets: Modeling and finite element simulations. Journal of Applied Polymer Science, 2007, 106: 1718-1724.

[14] A. Makradi, S. Ahzi, S. Belouettar, and D. Ruch. Thermoforming process of semicrystalline polymeric sheets: Modeling and finite element simulations. Polymer Science: Series A, 2008, 50: 550-557.

[15] C. Yang and S. W. Hung. Optimising the thermoforming process of polymeric foams: an approach by using the Taguchi method and the utility concept. The International Journal of Advanced Manufacturing Technology.2004, 24(5): 353-360.

[16] H. Bae, H.-J. Lee, and K. Park. Effect of vibration transmission direction in ultrasonic thermoforming on the formability of micro-corrugations. International Journal of Precision Engineering and Manufacturing, 2017, 18: 697-703.

[17] W. H, Z. Jiang, T. Wang, Y. Wang, and X. Hu. Remanufacturing Scheme Design for Used Parts Based on Incomplete Information Reconstruction. Chinese journal of mechanical engineering, 2020, 33: 41 .

[18] N. P. Suh. Axiomatic Design: Advances and Applications. Oxford University Press, 2001.

[19] Q-J. Peng, Y-H Liu, J. Zang and P.-H. Gu. Personalization for massive product innovation using open architecture. Chinese journal of mechanical engineering, 2018, 31: 34. 
[20] K. D. Lee, N. P. Suh, and J.-H. Oh. Axiomatic Design of Machine Control System. CIRP Annals, 2001, 50(1): 109-114.

[21] B.-S. Jang, Y.-S. Yang, Y.-S. Song, Y.-S. Yeun, and S.-H. Do. Axiomatic design approach for marine design problems. Marine Structures, 2002, 15(1): 35-56.

[22] T.-S. Bae and K.-H. Lee. Structural design of a main starting valve based on the first axiom. International Journal of Precision Engineering and Manufacturing, 2012, 13: 685-691.

[23] K.-H. Hwang, K.-H. Lee, G.-J. Park, B.-L. Lee, Y.-C. Cho, and S.-H. Lee. Robust design of a vibratory gyroscope with an unbalanced inner torsion gimbal using axiomatic design. Journal of Micromechanics and Microengineering, 2002, 13(1): 8-17.

[24] J. M. Park. Improved methodology for RMS adaptability evaluation. International Journal of Precision Engineering and Manufacturing, 2017, 18: 1537-1546

[25] I. C. Bang and G. Heo. An axiomatic design approach in development of nanofluid coolants. Applied Thermal Engineering, 2009, 29(1): 75-90.

[26] R. J. Urbanic and W. H. El Maraghy. Using axiomatic design with the design recovery framework to provide a platform for subsequent design modifications. CIRP Journal of Manufacturing Science and Technology, 2009, 1(3): 165-171.

[27] D. Tang, G. Zhang, and S. Dai. Design as integration of axiomatic design and design structure matrix. Robotics and Computer-Integrated Manufacturing, 2009, 25(3): 610-619.

[28] F.-T. Weng and S.-M. Jenq. Application integrating axiomatic design and agile manufacturing unit in product evaluation. The International Journal of Advanced Manufacturing Technology, 2012, 63: 181-189.

[29] J. A. Carnevalli, P. A. C. Miguel, and F. A. Calarge. Axiomatic design application for minimising the difficulties of QFD usage. International Journal of Production Economics, 2010, 125(1): 1-12.

[30] A. M. Gonçalves-Coelho, G. Neştian, M. Cavique, and A. Mourão. Tackling with redundant design solutions through axiomatic design. International Journal of Precision Engineering and Manufacturing, 2012, 13(10): 1837-1843.

[31] H. Panday and B. Bhattacharya. Fusion of TRIZ and Axiomatic Design Principles: An Investigation in Scalability of System Design Processes to Contemporary Design Frameworks. Proceedings of Research into Design for a Connected World, Singapore, 2019, 99-108.

[32] J. H. Yang, K. Y. Lee, and C. Y. Dong. Application of the axiomatic design methodology to the design of PBGA package with polyimide coating layer. KSME International Journal, 2004, 18(9): 1572-1581.

[33] E.-P. Hong and G.-J. Park. Modular design method based on simultaneous consideration of physical and functional relationships in the conceptual design stage. Journal of Mechanical Science and Technology, 2014, 28: 223-235.

[34] W. Yi, Y. Zeng, W. Wang, X. Tang, X. Liu and F. Meng. Optimal Design and Force Control of a Nine-Cable-Driven Parallel Mechanism for Lunar Takeoff Simulation. Chinese journal of mechanical engineering, 2019, 32: 73.

[35] G. Taguchi, S. Chowdhury, and $\mathrm{Y}$. Wu, Introduction to the Signal-to-Noise Ratio. Taguchi's Quality Engineering Handbook, Wiley-Interscience, 2004, 221-238.

[36] T. K. Nguyen, C. J. Hwang, and B.-K. Lee. Numerical investigation of warpage in insert injection-molded lightweight hybrid products.
International Journal of Precision Engineering and Manufacturing, 2017, 18: 187-195.

[37] K. Nguyen Trieu and B.-K. Lee. Post-processing of FDM parts to improve surface and thermal properties. Rapid Prototyping Journal, 2018, 24(7): 1091-1100.

[38] H. Qiu, W. Fang. Train Vehicle Structure Design from the Perspective of Evacuation. Chinese journal of mechanical engineering, 2019, 32: 88.

[39] Z. Jiang, D. Gao, Y. Lu, X. Liu. Optimization of cutting parameters for trade-off among carbon emissions, surface roughness, and processing time. Chinese journal of mechanical engineering, 2019, 32: 94.

[40] Y. Wang, Y. Gan, H. Liu, L. Han, J, W, K. Liu. Surface Quality Improvement in Machining an Aluminum Honeycomb by Ice Fixation. Chinese journal of mechanical engineering, 2020, 33: 20.

[41] B. J. Jeon, Y. H. Kim, K. S. Lee, S. W. Cha, G. J. Nam, C. Y. Park, etal. Parameter Design of a Coaxial Cable Insulation Manufacturing Process Using Axiomatic Design and the Taguchi Method.Polymer-Plastics Technology and Engineering, 2008, 47(8): 785-790

\section{Biographical notes}

Trieu KhoaNguyen, born in 1981, is currently is Head of Manufacturing Division of the Faculty of Mechanical Engineering, Industrial University of Ho Chi Minh City, Vietnam. He received his Ph.D in Mechanical Engineering from Chonnam National University, Korea. His research interests include polymer science, multiscale manufacturing processes, 3D printing technology.

E-mail: nguyenkhoatrieu@iuh.edu.vn

Anh-Duc Pham,born in 1986, received Ph.D. degree from Soongsil University, Korea. He was a research associate in the IMSLab - Soongsil University and is currently a researcher/lecturer at the Faculty of Mechanical Eng., University of Science and Technology- The University of Danang. Dr. Pham's research interests are mechatronics, control \& precision machine design, sustainable design \&manufacturing, applications of nanomaterials.

E-mail: ducpham@dut.udn.vn

Minh Quang Chau, born in 1970, received Ph.D. degree from the Institute of Mechanical Engineering, Hunan University, China, in 2013. He is currently the Dean of the Faculty of Mechanical Engineering, Industrial University of Ho Chi Minh City, Vietnam. His research interests are manufacturing, material, mechanics, reliability and optimization.

E-mail: chauminhquang@iuh.edu.vn

Hai Son Nguyen, born in 1987, received his received M.S. degree from University of Technology, Vietnam National University - Ho Chi Minh City in 2013. Mr. Nguyen's research interests include metal \& plastic processing, manufacturing processes \& application of $3 \mathrm{D}$ printing technology. 
Figures

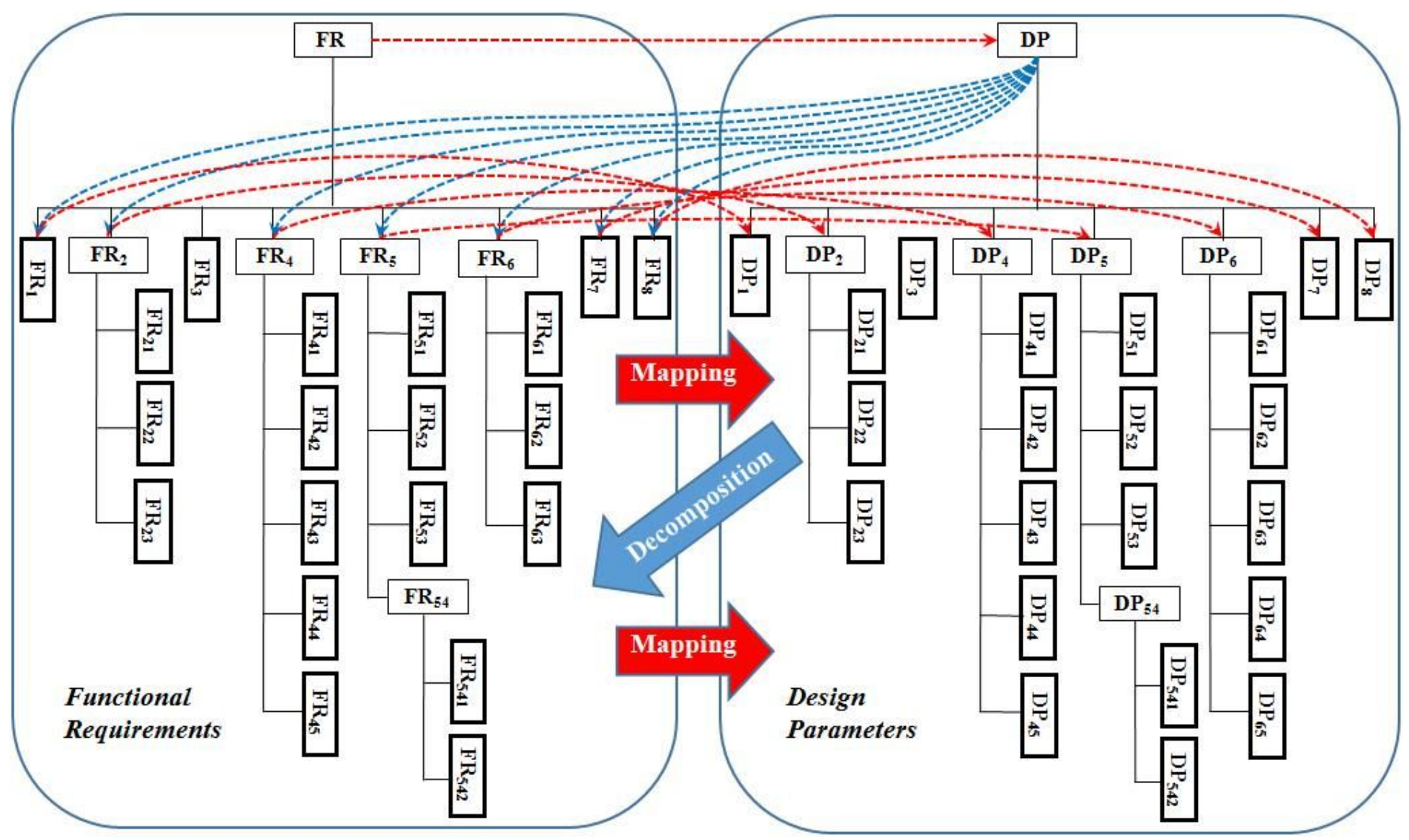

Figure 1

Mapping and decomposition process 


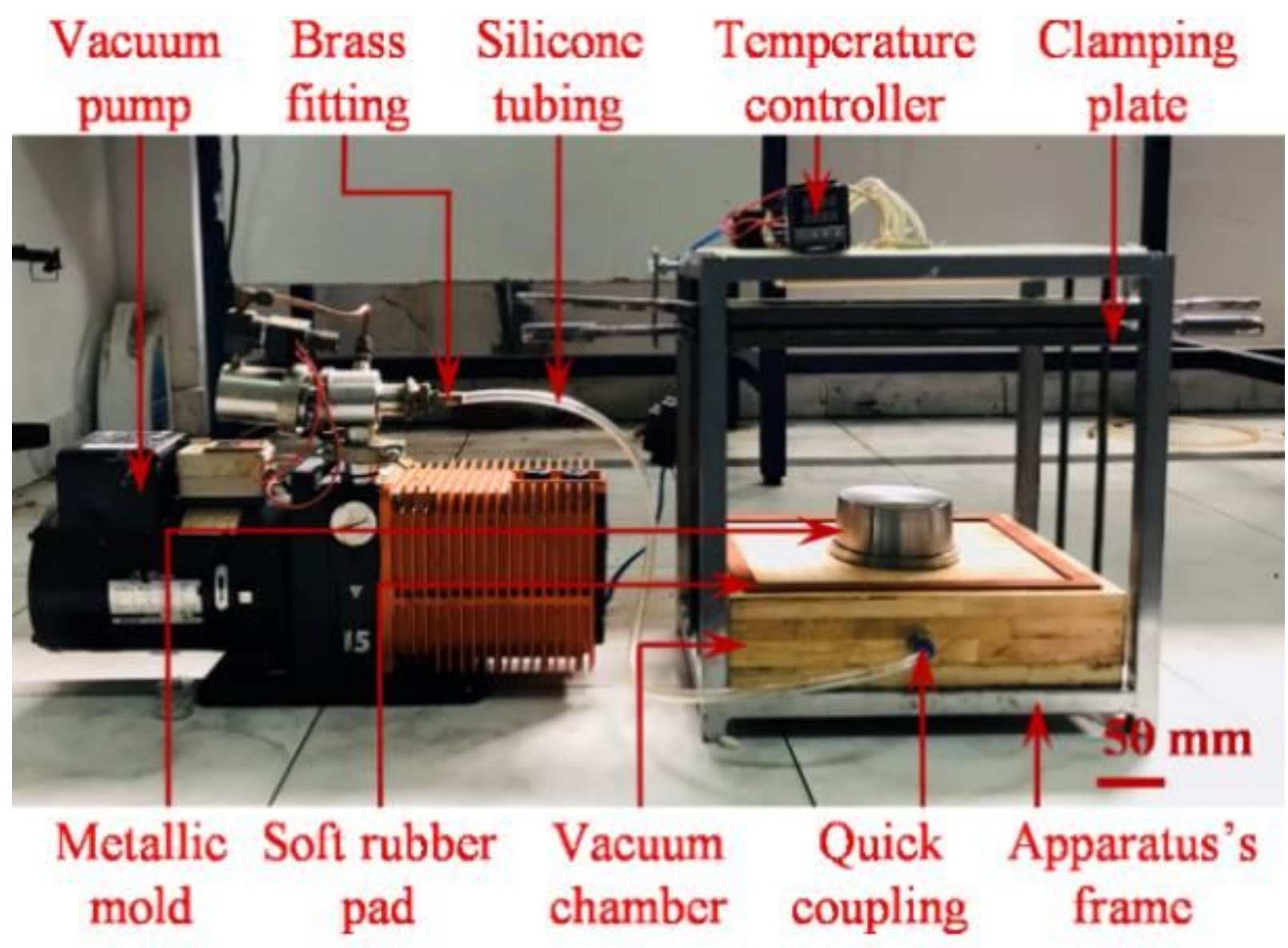

Figure 2

Photograph of the lab-scale thermoforming setup employing the ADT 


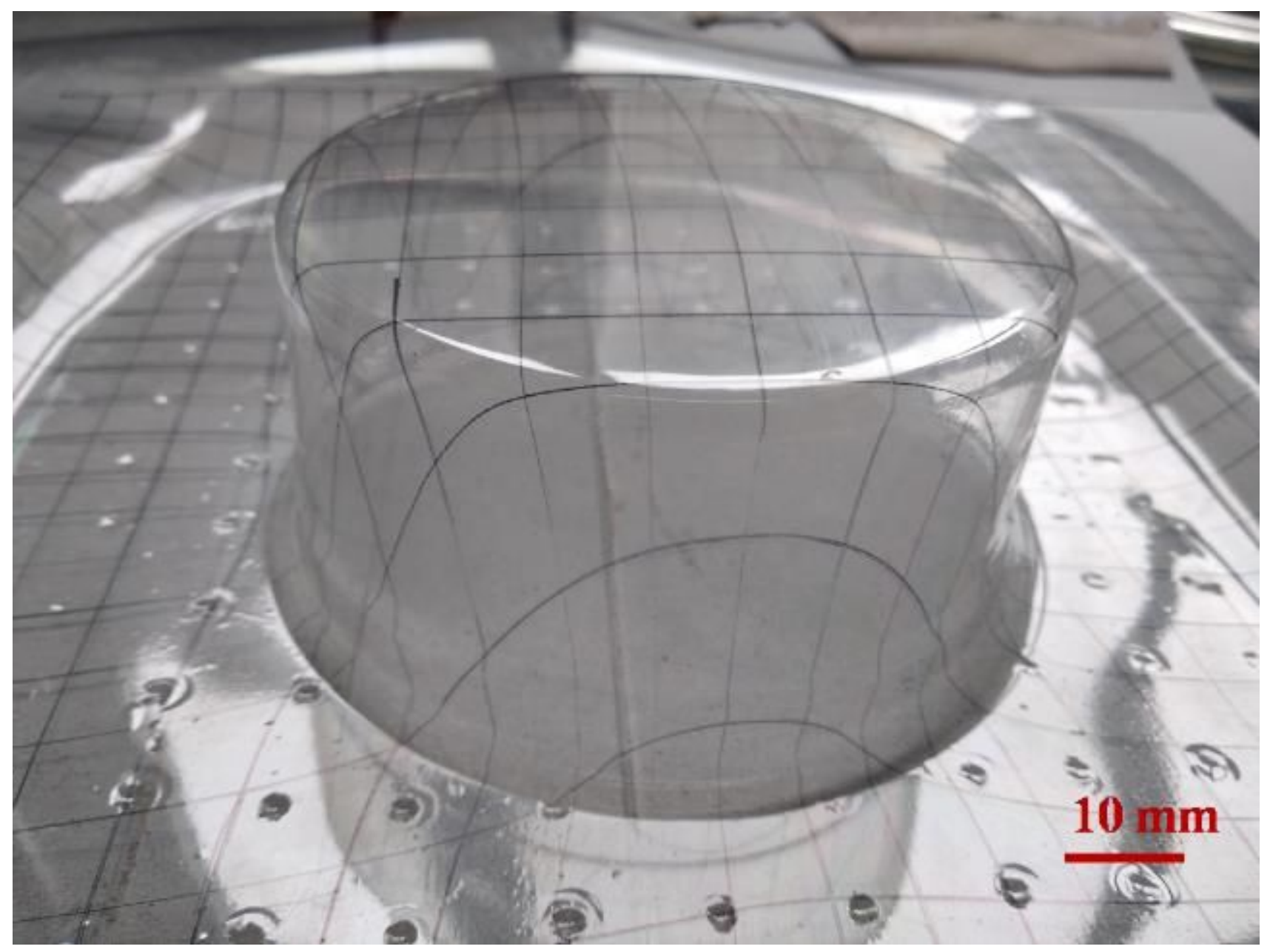

Figure 3

Thermoformed sample with its deformed net 


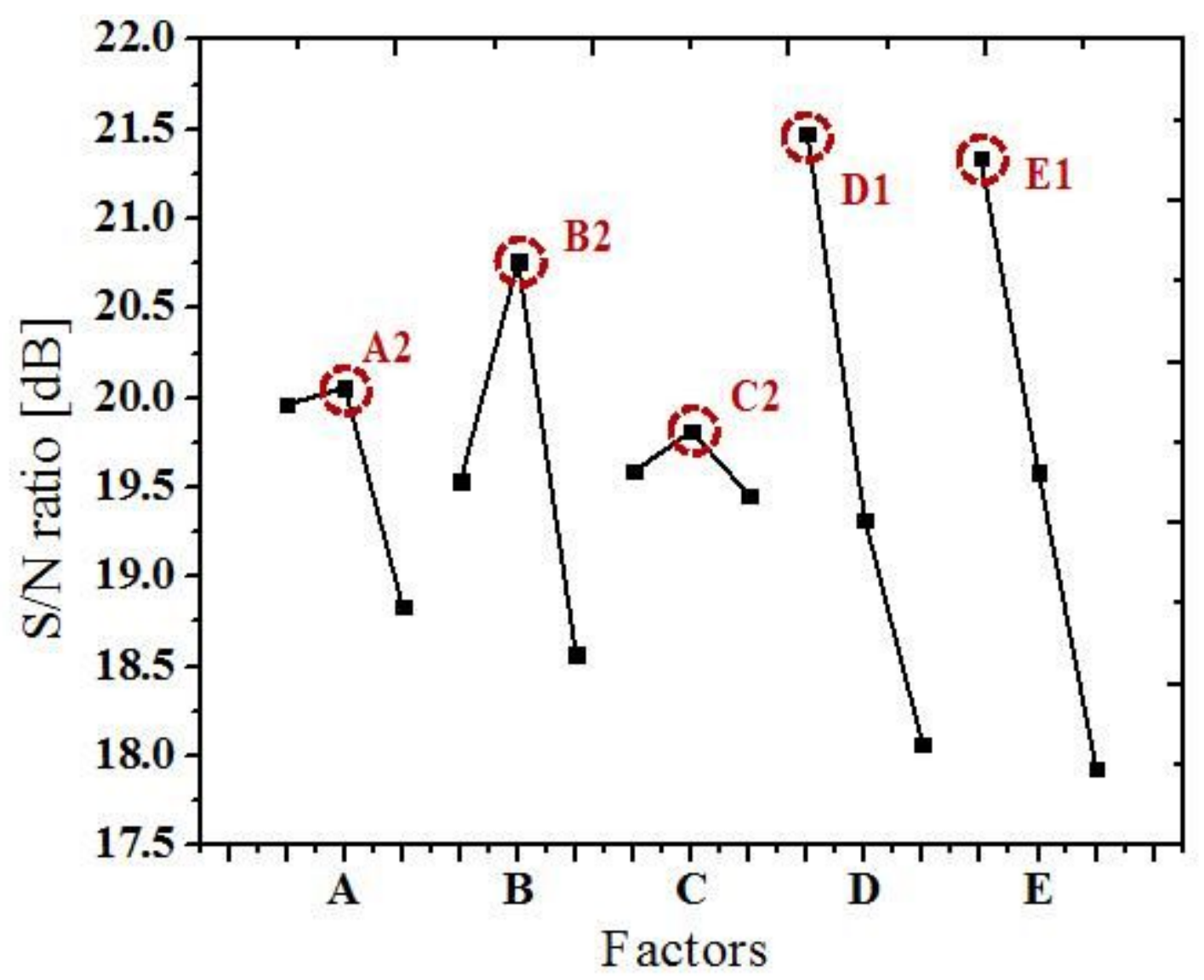

Figure 4

Results of S/N ratio study illustrating the influence of processing conditions on the uniformity

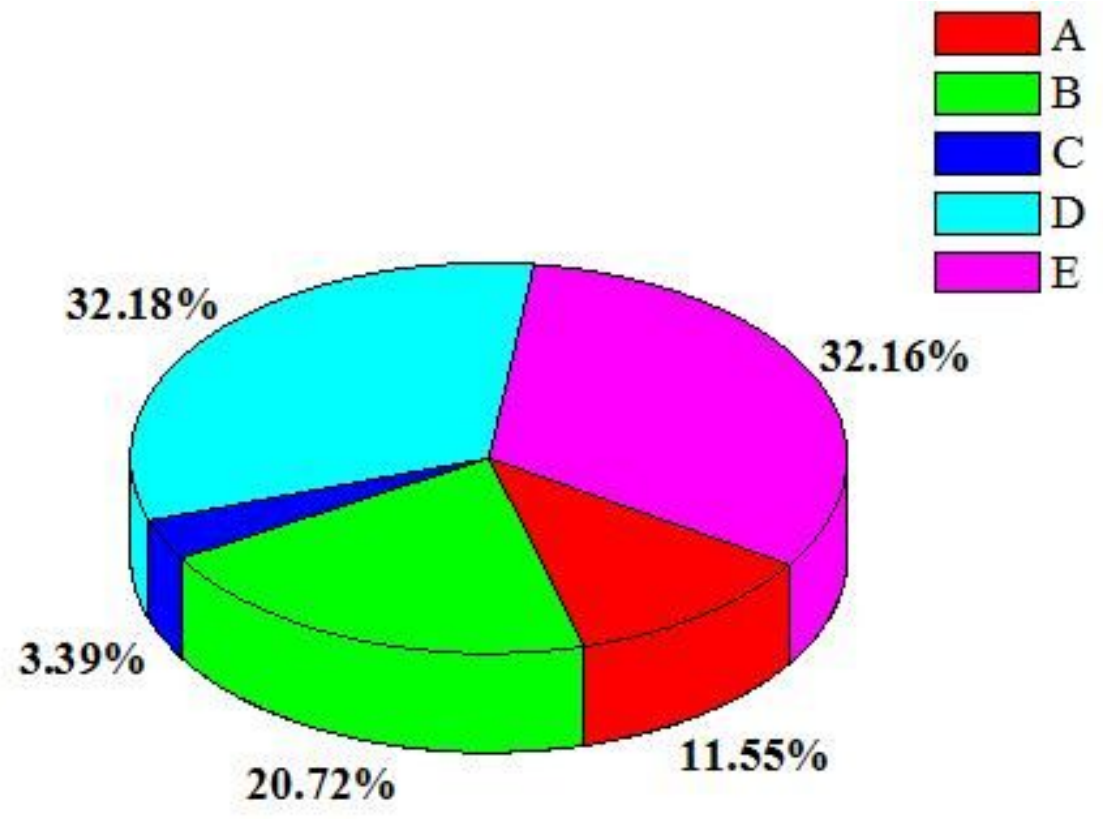

Figure 5 
Contribution chart of each processing condition in the $\mathrm{S} / \mathrm{N}$ ratio study

\section{Main Effects Plot for SN ratios}

\section{Main Effects Plot for SN ratios \\ Data Means}

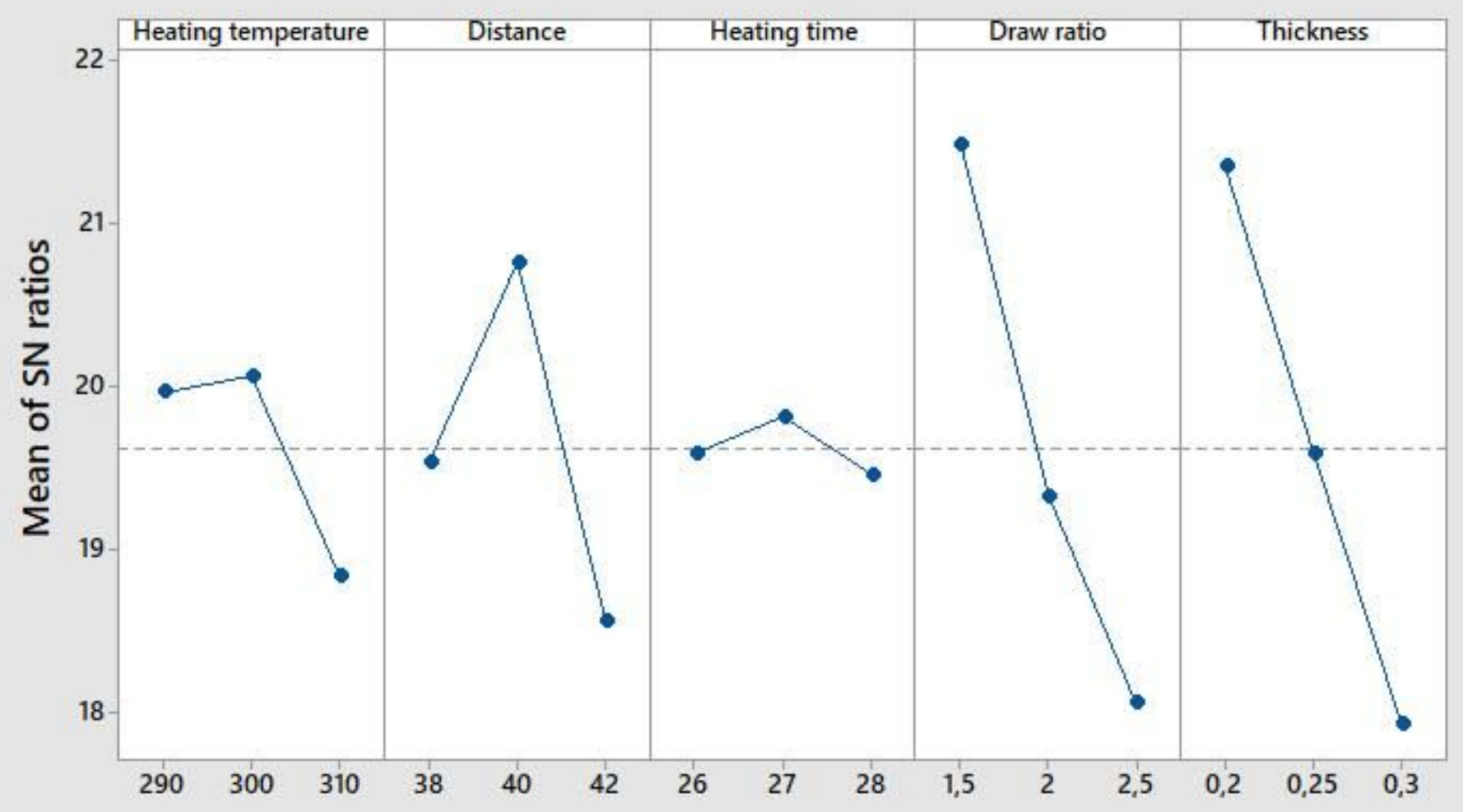

Signal-to-noise: Smaller is better

Figure 6

Validation using a commercial software solution - Minitab ${ }^{\circledR}$ 


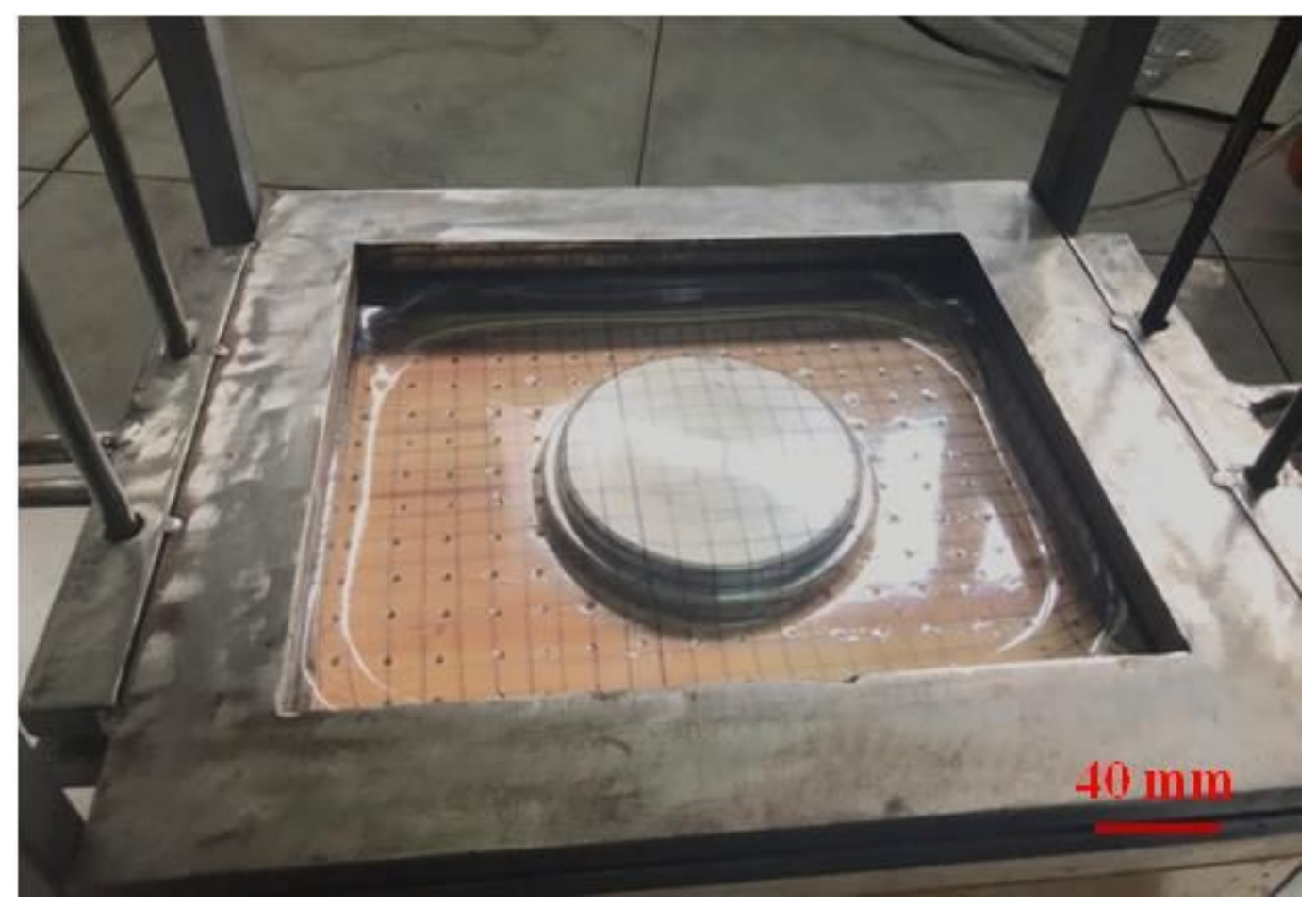

Figure 7

Validation experiment under the recommended parameters from $\mathrm{S} / \mathrm{N}$ ratio analysis

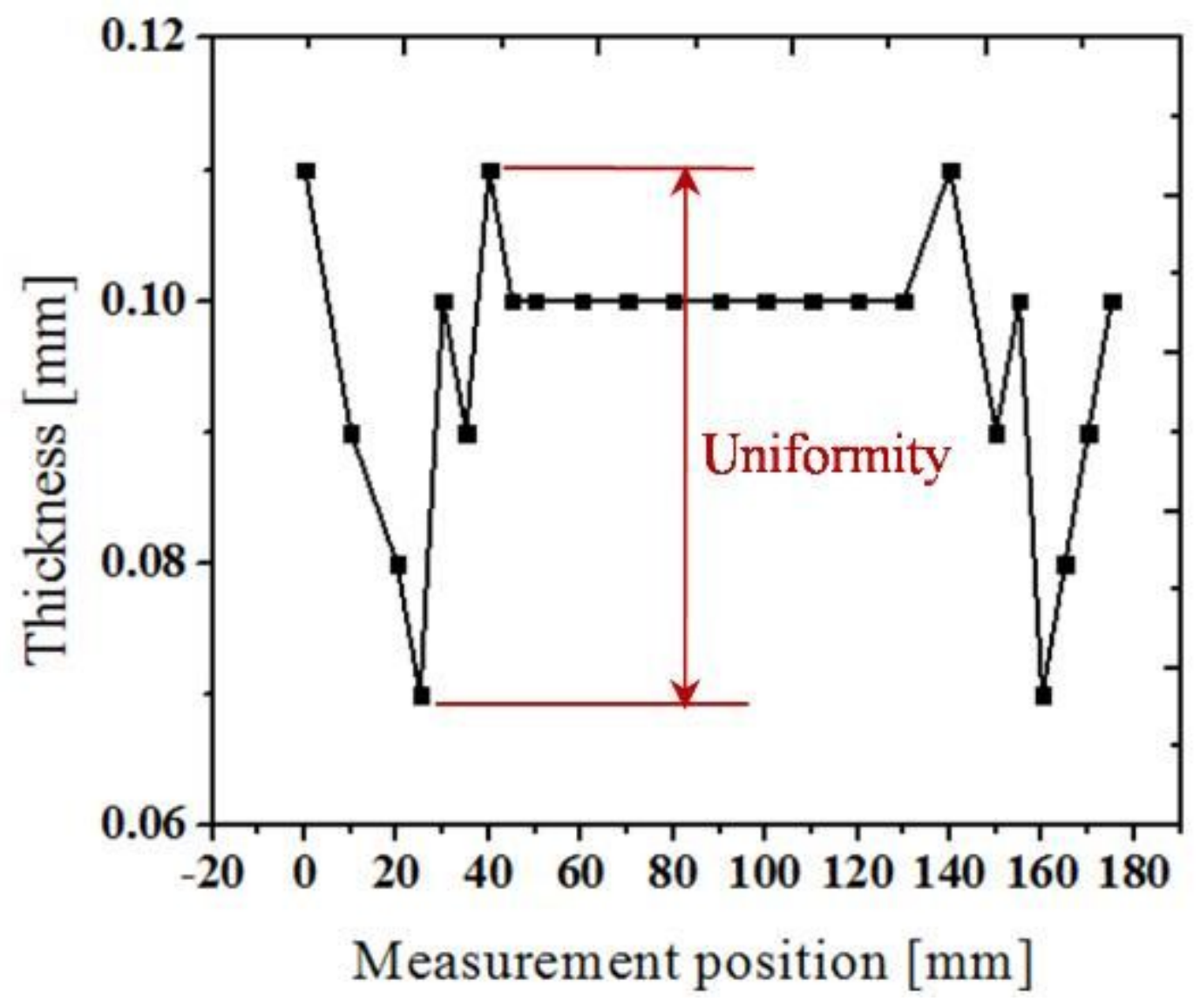

Figure 8 
Thickness distribution of the validation sample and its uniformity value 